\title{
Karakterisasi Arus-Tegangan Sensor Gas Hidrogen Dari Bahan Komposit Semikonduktor $\mathrm{TiO}_{2}-\mathrm{SnO}_{2}$
}

\author{
Reza Hamdani*, Elvaswer \\ Laboratorium Fisika Material, Jurusan Fisika \\ Fakultas Matematika dan Ilmu Pengetahuan Alam Universitas Andalas \\ Kampus Unand LimauManis, Padang, 25163 Indonesia \\ *rezahamdani4@gmail.com
}

\begin{abstract}
ABSTRAK
Telah dilakukan karakterisasi sensor gas hidrogen berupa pelet dengan bahan komposit $\mathrm{TiO}_{2}-\mathrm{SnO}_{2}$. Pelet sensor gas hidrogen dibuat dengan komposisi yang berbeda. Proses pembuatan sensor gas hidrogen diawali dengan pencampuran bahan, kalsinasi pada temperatur $500^{\circ} \mathrm{C}$ selama 4 jam, penggerusan, kompaksi dan sintering pada temperatur $700^{\circ} \mathrm{C}$ selama 4 jam dengan mengunakan metode reaksi dalam keadaan padat. Sensor gas hidrogen diuji pada temperatur ruang dengan mengukur nilai $I-V$, nilai sensitivitas, nilai konduktivitas, waktu respon dan karakterisasi XRD. Berdasarkan pengukuran I-V bahwa sampel $70 \% \mathrm{~mol} \mathrm{SnO}_{2}+30 \% \mathrm{~mol} \mathrm{TiO}_{2}$ memiliki sensitivitas tertinggi yaitu 5,58 pada tegangan 27

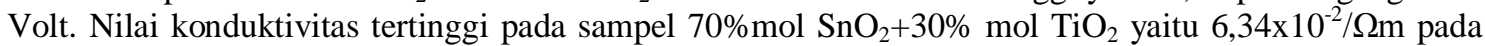
lingkungan hidrogen. Waktu respon sampel $70 \% \mathrm{~mol} \mathrm{SnO}_{2}+30 \% \mathrm{~mol} \mathrm{TiO}_{2}$ pada tegangan 27 volt adalah 36 sekon. Hasil XRD menunjukaan ukuran kristal $70 \% \mathrm{~mol} \mathrm{SnO}_{2}+30 \% \mathrm{~mol} \mathrm{TiO}_{2}$ adalah 141,64 nm lebih kecil dibandingkan dengan bahan $\mathrm{SnO}_{2}$ dan $\mathrm{TiO}_{2}$ tanpa doping yaitu 149,101 nm dan 159,25 nm Kata kunci: konduktivitas, sensitivitas, sensor gas hidrogen, $\mathrm{TiO}_{2}-\mathrm{SnO}_{2}$, waktu respon.
\end{abstract}

\section{ABSTRACT}

The characterization of hydrogen gas sensor in the form of pellets made of $\mathrm{SnO}_{2}-\mathrm{TiO}_{2}$ was performed. The hydrogen gas sensor pellets are made with different compositions. The preparation of hydrogen gas sensor starts with the mixing of the materials, calcination at $500^{\circ} \mathrm{C}$ for 4 hours, grinding, compacting and sintering at $700^{\circ} \mathrm{C}$ for 4 hours used solid state reaction method. Hydrogen gas sensor was tested at room temperature by investigating the measuring I-V value, sensitivity, conductivity, response time and XRD characterization. Based on measured I-V characteristics the sample of $70 \% \mathrm{~mol}$ of $\mathrm{SnO}_{2}+30 \% \mathrm{~mol}$ of $\mathrm{TiO}_{2}$ shows the highest sensitivity. The sensitivity is 5,58 at 27 Volt. The sample of $70 \%$ mol of $\mathrm{SnO}_{2}+$ $30 \%$ mol of $\mathrm{TiO}_{2}$ also has the highest conductivity at 6,34 $\times 10^{-2} / \mathrm{\Omega m}$ in the hydrogen. The response time of the sample $70 \%$ mol of $\mathrm{SnO}_{2}+30 \%$ of $\mathrm{TiO}_{2}$ at 27 volt is $36 \mathrm{~s}$. XRD results indicate that the crystal size of $70 \%$ mol of $\mathrm{SnO}_{2}+30 \%$ mol of $\mathrm{TiO}_{2}$ was 141,64 nm smaller than $\mathrm{SnO}_{2}$ and $\mathrm{TiO}_{2}$ without doping was $149,101 \mathrm{~nm}$ and $159,25 \mathrm{~nm}$.

Keywords: conductivity, sensitivity, hydrogen gas sensor, $\mathrm{SnO}_{2}-\mathrm{TiO}_{2}$, response time

\section{PENDAHULUAN}

Hidrogen merupakan unsur paling melimpah dengan persentase $75 \%$ dari total massa unsur alam semesta. Hidrogen dimanfaatkan pada berbagai bidang antara lain dapat digunakan sebagai bahan bakar pada kendaraan bermotor (Hübert dkk., 2014). Hidrogen merupakan bahan bakar ramah lingkungan, dimana energi yang dihasilkan sangat bersih karena hanya menghasilkan uap air sebagai emisi. Hidrogen tidak bewarna, tidak berbau, bersifat non-logam, bervalensi tunggal, dan merupakan gas yang sangat mudah terbakar pada konsentrasi $4 \%$ di udara bebas (Yang dkk., 2014).

Hidrogen juga mempunyai kekurangan pada penyimpanannya. Hidrogen seringkali tidak terdeteksi oleh indera penciuman manusia jika terjadi kebocoran sehingga dapat mengakibatkan kebakaran. Resiko penggunaan gas hidrogen seperti kebakaran dapat diminimalisir apabila ada sensor yang mampu mendeteksi kebocoran gas tersebut. Bahan semikonduktor oksida yang memiliki kemampuan sebagai sensor gas antara lain adalah $\mathrm{TiO}_{2}$, $\mathrm{ZnO}, \mathrm{CuO}$, dan $\mathrm{SnO}_{2}$ (Wang dan $\mathrm{Hu}, 2012$ ).

$\mathrm{TiO}_{2}$ dikenal sebagai material metal oksida yang memiliki kemampuan sebagai sensor. $\mathrm{TiO}_{2}$ memiliki beberapa kelebihan di antaranya stabilitas termal yang baik, permukaan yang mudah bereaksi secara kimia, memiliki sifat listrik yang baik sehingga banyak digunakan dalam pembuatan sensor gas (Yadav dkk, 2011). Sensitivitas sensor gas dapat ditingkatkan dengan cara mendoping bahan utama dengan logam mulia atau bahan metal oksida. Bahan logam mulia 
butuh biaya yang lebih mahal dan cukup sulit diperoleh dibandingkan dengan bahan metal oksida (Patil dkk, 2011). Bahan yang digunakan adalah material $\mathrm{SnO}_{2}$, bahan ini merupakan bahan metal oksida yang mempunyai titik leleh dan titik lebur yang tinggi, merespon sejumlah gas dengan baik dan ketersediaan bahan cukup melimpah. $\mathrm{SnO}_{2}$ memiliki masa pemakaian yang lebih lama dan relatif stabil dan daya tahan yang tinggi (Shaposnik dkk, 2012).

Penelitian bahan sensor gas semikonduktor metal oksida pada temperatur ruang $30^{\circ} \mathrm{C}$ masih sangat sedikit. Sensor gas yang bekerja pada temperatur ruang membutuhkan energi yang kecil untuk dapat mendeteksi gas pada suatu lingkungan, sehingga akan sangat baik apabila dapat dikembangkan bahan sensor gas yang bekerja pada temperatur ruang (Maiyeni dan Elvaswer, 2012). Penelitian tentang gas hidrogen pernah dilakukan oleh (Mondal dkk, 2014) dengan menggunakan bahan komposit $\mathrm{ZnO}-\mathrm{SnO}_{2}$, hasil yang didapat yaitu waktu respon sebesar 60 detik untuk $10000 \mathrm{ppm}$ gas hidrogen pada suhu $150{ }^{\circ} \mathrm{C}$. Penelitian tentang gas hidrogen juga pernah dilakukan oleh Maiyeni (2016) dengan menggunakan bahan $\mathrm{CuO}$ didoping $\mathrm{TiO}_{2}$. Hasil yang didapat nilai sensitivitas sebesar 2,8 waktu respon sebesar 42 detik pada suhu kamar.

Pada penelitian ini dibuat sensor dari bahan komposit semikonduktor $\mathrm{TiO}_{2}-\mathrm{SnO}_{2}$ dengan metode keadaan padat atau dalam bentuk pelet. Sensor gas dalam keadaan padat menunjukkan kemampuan respon sensor yang cepat, penggunaan yang sederhana dan harga yang lebih murah (Patil dkk, 2011). Penelitian dilakukan untuk mengatasi permasalahan dimana sensitivitas sensor masih rendah, waktu respon masih lama dan suhu operasional masih tinggi.

\section{METODE}

\subsection{Persiapan Pebuatan Pelet $\mathrm{TiO}_{2}-\mathrm{SnO}_{2}$}

Pada penelitian ini telah dibuat sampel dengan perbandingan persentase mol $\mathrm{TiO}_{2^{-}}$ $\mathrm{SnO}_{2}$ adalah 70:30, 60:40, 50:50, 40:60, 30:70, 100:0, 0:100 dimana massa masing-masing sampel adalah $0,5 \mathrm{~g}$. Reaksi kimia yang terjadi untuk mengetahui persentase massa dari masing masing sampel pada penelitian ini adalah :

$$
{ }_{x} \mathrm{SnO}_{2}+{ }_{(1-x)} \mathrm{TiO}_{2} \rightarrow \mathrm{Sn}_{x} \mathrm{Ti}_{(1-x)} \mathrm{O}_{2}
$$

Sampel digerus selama 10 menit agar sampel menjadi halus, dan dikalsinasi pada suhu $500{ }^{\circ} \mathrm{C}$ selama 4 jam. Setelah proses kalsinasi bahan digerus kembali, agar butir-butir yang menggumpal menjadi lebih halus. Bahan dikompaksi sehingga berbentuk pelet, kemudian pellet di-sintering pada suhu $700{ }^{\circ} \mathrm{C}$ selama 4 jam.

\subsection{Karakterisasi Sensor Gas Hidrogen}

Pelet yang telah disinter diuji seperti skema rangkaian pada Gambar 1. Skema di atas memperlihatkan bahwa alat pengujian berfungsi untuk mengalirkan gas hidrogen. Pelet dirangkai bias maju dengan menghubungkan salah satu elektroda dengan kutub positif sedangkan elektroda lainnya dengan kutub negatif, dan untuk bias mundur polaritasnya dibalik. Amperemeter dihubungkan secara seri dengan sumber tegangan dan pelet. Pengukuran bias maju dan bias mundur diberikan variasi tegangan dari -30 V sampai $30 \mathrm{~V}$ dengan kenaikan $3 \mathrm{~V}$.

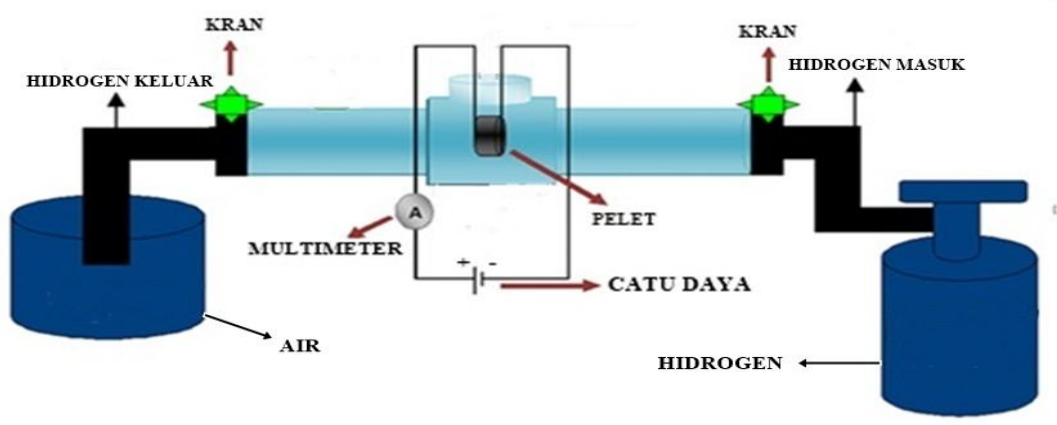

Gambar 1 Skema rangkaian alat pengujian sensor hidrogen 
Karakteristik $I-V$ diukur untuk menentukan sensitivitas dan konduktivitas sensor. Nilai sensitivitas dan konduktivitas dihitung menggunakan persamaan (2) dan persamaan (3). Nilai sensitivitas dapat ditentukan dengan menggunakan persamaan :

$$
S=\frac{\text { Ihidrogen }}{\text { Iudara }}
$$

dengan $I_{\text {hidrogen }}$ adalah arus pada lingkungan hidrogen $(\mathrm{mA}), I_{\text {udara }}$ adalah arus pada lingkungan udara (mA), dan $S$ merupakan sensitivitas.

Konduktivitas menunjukkan kemampuan suatu bahan untuk mengalirkan arus listrik. Nilai konduktivitas dapat dihitung menggunakan persamaan :

$$
\sigma=\frac{L}{R A}
$$

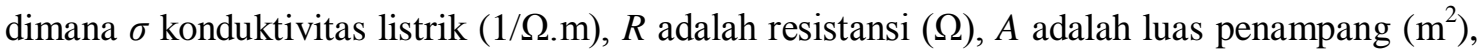
dan $L$ adalah ketebalan sampel (m).

XRD digunakan untuk melihat ukuran kristal dari sampel. Ukuran kristal dapat dihitung menggunakan persamaan :

$$
D=\frac{0,9 \lambda}{B \cos \theta}
$$

dimana $\mathrm{D}$ adalah ukuran kristal, $\lambda$ adalah panjang gelombang sinar-X yang digunakan, $\theta$ adalah sudut Bragg, B adalah lebar penuh garis difraksi pada saat intensitas setengah maksimum (Full Width Half Maximum, FWHM), dan 0,9 merupakan nilai konstanta material untuk partikel bulat.

\section{HASIL DAN DISKUSI}

\subsection{Karakteristik I-V pada Lingkungan Hidrogen dan Udara}

Karakteristik $I-V$ masing-masing sampel pada lingkungan hidrogen dan udara dapat ditampilkan sebagai grafik arus-tegangan. Karakterisasi $I-V$ pada masing-masing sampel dapat ditunjukkan pada Gambar 2.

Gambar 2 (a) dan (b) menunjukan grafik karakteristik $I-V$ dimana arus pada lingkungan hidrogen hampir overlap dengan arus pada lingkungan udara. Hal ini disebabkan sebelumTiO dan $\mathrm{SnO}_{2}$ dijadikan komposit mempunyai energi gap lebih besar dibandingkan setelah dijadikan komposit sehingga elektron susah untuk melompat dari pita valensi ke pita konduksi.

Gambar 2 (c) dan (e) memperlihatkan arus pada lingkungan hidrogen dan arus lingkungan udara tidak jauh berbeda dibandingkan sampel sebelum dijadikan komposit, tetapi memiliki perbandingan arus pada lingkungan hidrogen dengan arus pada lingkungan udara lebih besar dibandingkan sampel sebelum dijadikan komposit, hal ini disebabkan setelah dijadikan komposit material semikonduktor menyumbang elektron sehingga dapat memperkecil daerah deplesi antar muka butir partikel akibatnya elektron mudah untuk berpindah dari satu partikel ke partikel lainya.

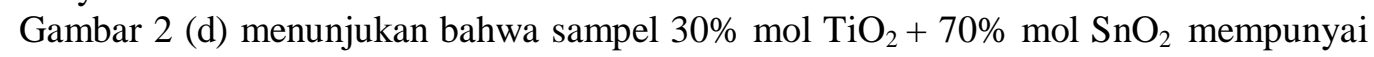
perbandingan arus pada lingkungan hidrogen dengan arus pada lingkungan udara adalah yang terbesar yaitu 5,58. Hal ini disebabkan karena arus pada lingkugan hidrogen optimum bereaksi dengan oksida yang terdapat pada sampel komposit semikonduktor tersebut sehingga dapat memperkecil daerah deplesi antar muka butir partikel akibatnya elektron mudah untuk berpindah dari satu partikel ke partikel lainya.

Gambar 2 (f) menunjukan perbandingan arus pada lingkungan hidrogen dengan arus pada lingkungan udara yang paling rendah, hal ini disebabkan karena reaksi antara hidrogen dan permukaan oksida menurun, sehingga interaksi elektron di dalam bahan sedikit.

Gambar 2(g) memperlihatkan bahwa arus di lingkungan hidrogen lebih tinggi dibandingkan arus di lingkungan udara. Hal ini disebabkan karena pada permukaan semikonduktor akan lebih banyak menyerap molekul-molekul hidrogen dibandingkan dengan molekul-molekul pada lingkungan udara. Molekul- molekul hidrogen yang terabsorbsi ini akan mengikat elektron bebas sehingga arus semakin tinggi. 

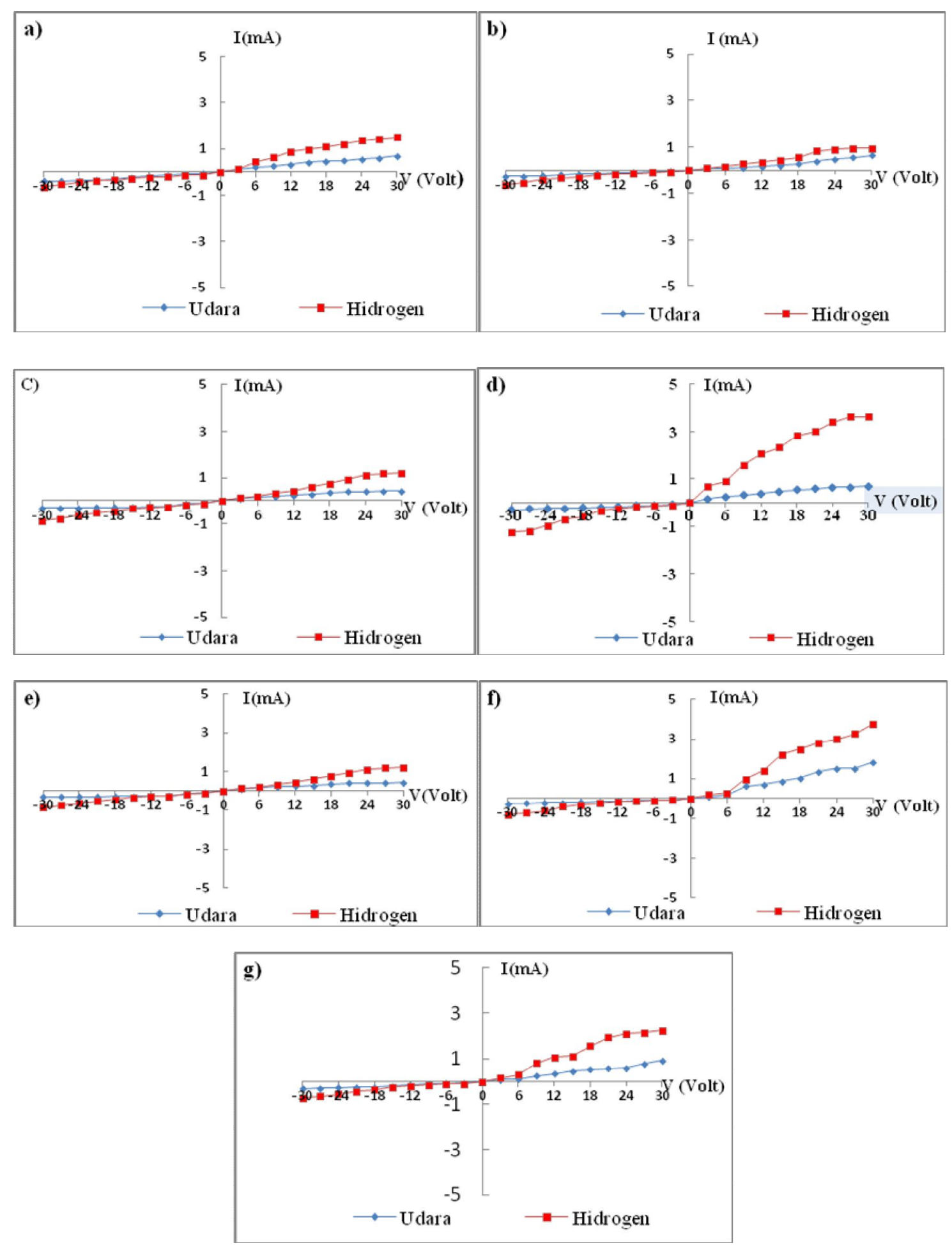

Gambar 2 Grafik karakteristik I-V pada lingkungan udara dan hydrogen untuk (a) $100 \%$ mol $\mathrm{TiO}_{2}$, (b) $100 \% \mathrm{~mol} \mathrm{SnO}_{2}$, (c) $60 \% \mathrm{~mol} \mathrm{TiO}_{2}+40 \% \mathrm{~mol} \mathrm{SnO}_{2}$, (d) $30 \% \mathrm{~mol} \mathrm{TiO}_{2}+70 \% \mathrm{~mol}$

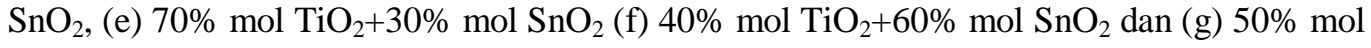
$\mathrm{TiO}_{2}+50 \% \mathrm{~mol} \mathrm{SnO}$

\subsection{Karakteristik Sensitivitas}

Sensitivitas sensor gas dapat diketahui berdasarkan grafik karakteristik I-V yang telah diperoleh dan dihitung menggunakan Persamaan 2. Perubahan nilai sensitivitas masing-masing sampel dapat dilihat pada Gambar 3. Gambar 3 dapat dilihat bahwa sensitivitas tertinggi ditunjukkan pada sampel komposit semikonduktor $\mathrm{TiO}_{2}-\mathrm{SnO}_{2}$ dengan persentase mol $30 \%$ 
$\mathrm{TiO}_{2}+70 \% \mathrm{SnO}_{2}$ yaitu 5,58 pada tegangan 27 volt pada bias maju. Hal ini disebabkan arus pada lingkugan hidrogen optimum bereaksi dengan oksida yang terdapat pada sampel komposit semikonduktor tersebut sehingga dapat memperkecil daerah deplesi antar muka butir partikel akibatnya elektron mudah untuk berpindah dari satu partikel ke partikel lainya.

Untuk sensitivitas yang rendah terjadi pada bahan komposit semikonduktor $70 \%$ mol $\mathrm{TiO}_{2}+30 \%$ mol $\mathrm{SnO}_{2}, \mathrm{SnO}_{2}$ dan $\mathrm{TiO}_{2}$ tanpa doping. Hal ini disebabkan karena reaksi antar hidrogen dan oksida menurun dan untuk sampel tanpa doping memiliki energi gap yang besar dan arus yang dihasilkan di ligkungan hidrogen kecil.

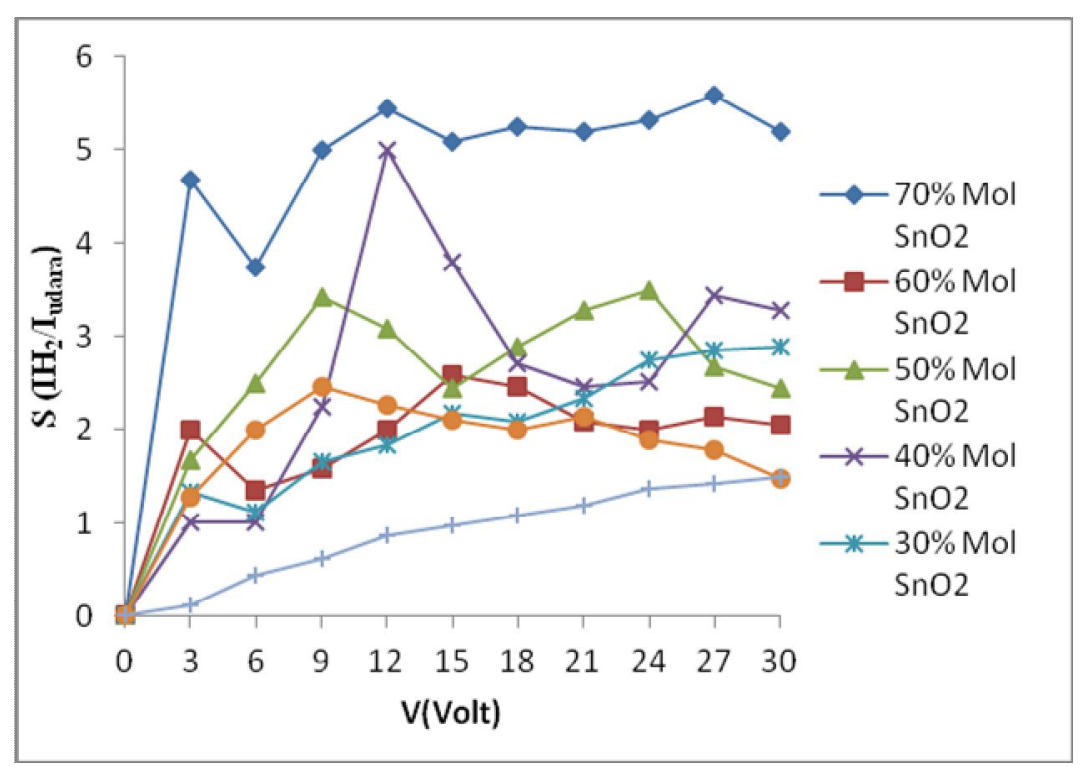

Gambar 3 Grafik perubahan sensitivitas terhadap tegangan untuk beberapa komposisi mol

$\mathrm{SnO}_{2}$

\subsection{Karakteristik Konduktivitas}

Nilai konduktivitas pada lingkungan udara maupun lingkungan hidrogen dapat dihitung menggunakan Persamaan 3. Nilai konduktivitas pada lingkungan hidrogen lebih besar dibandingkan dengan nilai konduktivitas pada lingkungan udara. Hal ini disebabkan oleh reaksi antara hidrogen dengan oksida pada permukaan partikel yang lebih besar pada lingkungan hidrogen dibandingkan pada lingkungan udara. Perubahan nilai konduktivitas sebelum dan sesudah dialiri gas hidrogen pada masing-masing sampel ditunjukkan pada Tabel 1.

Tabel 1 Perubahan konduktivitas pada lingkungan udara dan hidrogen

\begin{tabular}{|c|c|c|}
\hline \multirow{2}{*}{ Komposisi Sampel } & \multicolumn{2}{|c|}{ Konduktivitas $\left(10^{-2} /\right.$ S.m) } \\
\hline & Lingkungan Udara & Lingkungan Hidrogen \\
\hline $70 \% \mathrm{~mol} \mathrm{SnO}{ }_{2}+30 \% \mathrm{~mol} \mathrm{TiO}_{2}$ & 1,25 & 6,34 \\
\hline $60 \% \mathrm{~mol} \mathrm{SnO}{ }_{2}+40 \% \mathrm{~mol} \mathrm{TiO}$ & 2,09 & 4,00 \\
\hline $50 \% \mathrm{~mol} \mathrm{SnO} \mathrm{S}_{2}+50 \% \mathrm{~mol} \mathrm{TiO}_{2}$ & 1,13 & 1,24 \\
\hline $40 \% \mathrm{~mol} \mathrm{SnO}_{2}+60 \% \mathrm{~mol} \mathrm{TiO}_{2}$ & 0,32 & 3,04 \\
\hline $30 \% \mathrm{~mol} \mathrm{SnO} \mathrm{S}_{2}+70 \% \mathrm{~mol} \mathrm{TiO}_{2}$ & 0,39 & 1,62 \\
\hline $100 \% \mathrm{~mol} \mathrm{SnO}$ & 0,65 & 1,27 \\
\hline $100 \% \mathrm{~mol} \mathrm{TiO}_{2}$ & 1,07 & 2,37 \\
\hline
\end{tabular}

Konduktivitas pada lingkungan hidrogen mempunyai nilai tertinggi pada sampel $30 \%$ $\mathrm{TiO}_{2}+70 \% \mathrm{SnO}_{2}$ yaitu $6,34 \times 10^{-2} / \Omega$. m dibandingkan pada lingkungan udara. Hal ini disebabkan oleh terjadinya rekasi antar hidrogen dengan oksida yang dapat memperkecil daerah deplesi yang mengakibatkan elektron dengan mudah berpindah ke pita konduksi. 


\subsection{Karakteristik Waktu Respon}

Waktu respon sebuah sensor gas sangat penting untuk diketahui, karena dengan menghitung waktu respon dapat diketahui kemampuan suatu sensor gas dalam mendeteksi gas tertentu disekitarnya. .Waktu respon diukur pada sampel yang memiliki sensitivitas tertinggi yaitu pada sampel komposit $30 \% \quad \mathrm{TiO}_{2}+70 \% \quad \mathrm{SnO}_{2}$ pada tegangan $27 \mathrm{~V}$. Grafik hasil pengukuran waktu respon dapat dilihat pada Gambar 4. Pengukuran waktu respon dilakukan dalam selang waku tiap 3 detik di lingkungan udara hingga stabil, kemudian setelah di udara dilanjutkan dengan mengalirkan gas hidrogen sampai didapatkan nilai arus yang stabil. Sampel berada pada lingungan udara hingga arus stabil. Kemudian saat gas hidrogen dialirkan terjadi peningkatan arus secara signifikan sampai detik ke- $78 \mathrm{~s}$. Hal ini disebabkan karena gas hidrogen yang bereaksi dengan oksida mengakibatkan daerah deplesi mengecil sehingga arus meningkat. Waktu respon yang diperoleh pada sampel yaitu $42 \mathrm{~s}$.

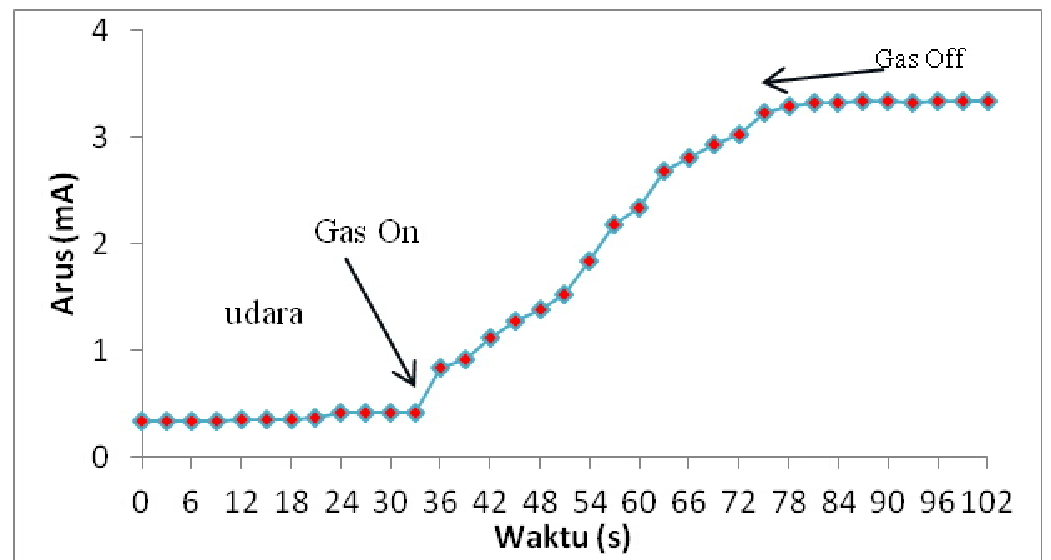

Gambar 4 Grafik waktu respon komposit $30 \% \mathrm{TiO}_{2}+70 \% \mathrm{SnO}_{2}$

\subsection{Karakteristik XRD}

Karakterisasi XRD telah dilakukan pada 3 sampel, yaitu sampel $100 \%$ mol $\mathrm{TiO}_{2}, 100$ mol $\mathrm{SnO}_{2}$ dan sampel yang memiliki sensitivitas tertinggi yaitu sampel $30 \% \mathrm{TiO}_{2}+70 \% \mathrm{SnO}_{2}$. Pola difraksi sinar-X ketiga sampel ditunjukan pada Gambar 5.

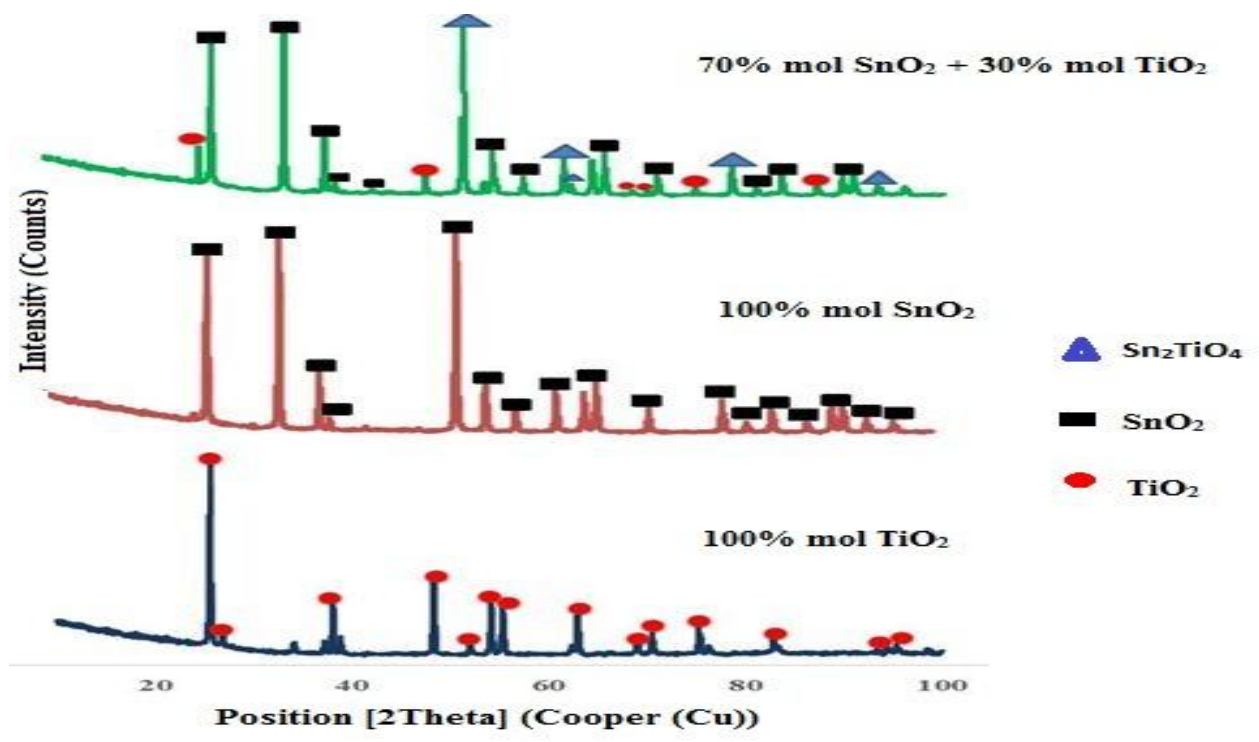

Gambar 5 Pola Difraksi Sinar-X Pada Sampel 100\% mol TiO $2,100 \% \mathrm{~mol} \mathrm{SnO}_{2}$ dan $70 \%$ $\mathrm{mol} \mathrm{SnO}_{2}+30 \% \mathrm{~mol} \mathrm{TiO}_{2}$.

Hasil XRD menunjukan pada sampel $30 \% \mathrm{TiO}_{2}+70 \% \mathrm{SnO}_{2}$ terdapat puncak-puncak baru yaitu $\mathrm{Sn}_{2} \mathrm{TiO}_{4}$. Munculnya puncak baru ini berarti terbentuknya senyawa yang baru yaitu 
$\mathrm{Sn}_{2} \mathrm{TiO}_{4}$. Gabungan dari bahan $\mathrm{SnO}_{2}$ dan $\mathrm{TiO}_{2}$ ini mempengaruhi ukuran kristal. Ukuran kristal pada ketiga sampel dihitung dengan mengunakan persamaan Scherer, ukuran kristal $100 \% \mathrm{SnO}_{2}$ yaitu $149,01 \mathrm{~nm}$ dan ukuran kristal $100 \% \mathrm{TiO}_{2}$ yaitu $159,25 \mathrm{~nm}$, sedangkan ukuran kristal sampel 30\% $\mathrm{TiO}_{2}+70 \% \mathrm{SnO}_{2}$ adalah 141,64 nm. Ukuran kristal dari komposit $\mathrm{SnO}_{2}+\mathrm{TiO}_{2}$ lebih kecil dibandingkan $\mathrm{TiO}_{2}$ dan $\mathrm{SnO}_{2}$ tanpa doping. Hal ini disebabkan karena ketika kedua bahan digabungkan, masing-masing bahan saling membelah diri sehingga terjadinya pertumbuhan kristal yang membuat ukuran kristal semakin kecil per satuan volume, dimana pada temperatur yang tinggi akan membuat ukuran kristal menjadi kecil. Berdasarkan grafik terlihat jelas bahwa sampel komposit $30 \% \mathrm{TiO}_{2}+70 \% \quad \mathrm{SnO}_{2}$ terbentuknya senyawa baru $\mathrm{Sn}_{2} \mathrm{TiO}_{4}$ dengan sistem kristal tetragonal, $\mathrm{TiO}_{2}$ dan $\mathrm{SnO}_{2}$ dengan sistem kristal tetragonal.

\section{KESIMPULAN}

Sensor mampu membedakan kondisi dilingkungan udara dengan lingkungan hidrogen, dengan arus tertnggi di lingkungan hidrogen adalah 3,76 $\mathrm{mA}$ dan arus tetinggi di lingkungan udara 1,83 mA. Nilai sensitivitas tertinggi diperoleh pada sampel $30 \% \mathrm{TiO}_{2}+70 \% \mathrm{SnO}_{2}$ sebesar 5,58 dengan tegangan operasional 27 volt pada suhu kamar. Konduktivitas lingkungan hidrogen lebih tinggi dibandingkan lingkungan udara. Konduktivitas tertinggi di lingkungan udara 2,09 $\times$ $10^{-2} / \Omega$.m dan lingkungan hidrogen adalah $6,34 \times 10^{-2} / \Omega$.m. Waktu respon sampel $30 \% \mathrm{TiO}_{2}+$ $70 \% \mathrm{SnO}_{2}$ adalah 42 detik pada tegangan $27 \mathrm{~V}$. Hasil XRD menunjukan terbentuknya senyawa baru $\mathrm{Sn}_{2} \mathrm{TiO}_{4}$ dan ukuran sampel $30 \% \quad \mathrm{TiO}_{2}+70 \% \quad \mathrm{SnO}_{2}$ yaitu $141,64 \mathrm{~nm}$ lebih kecil dibandingkan dengan $100 \% \mathrm{SnO}_{2}$ dan $\mathrm{TiO}_{2}$ murni yaitu 149,101 nm dan 159,25 nm.

\section{DAFTAR PUSTAKA}

Hübert, L. Boon-Brett, V. Palmisano, A. Bader, "Developments in gas sensor technology for hydrogen safety", International Journal of Hydrogen Energy, 35, 373-384, (2014).

Maiyeni,S dan Elvaswer, "Karakterisasi I-V Semikonduktor CuO Didoping $\mathrm{TiO}_{2}$ Sebagai Sensor Gas Hidrogen", Jurnal Fisika Unand, 3, 263-269 (2017).

Mondal, B. Basumatari, B. Das, J. Roychaudhury, C. Saha, H,“ZnO-SnO2 based composite type gas sensor for selective hydrogen sensing", Sensors and Actuator,194, 389- 396 (2014).

Patil, A., Dighavkar, C., Borse. R.,"Doped Thick Films as $\mathrm{CO}_{2}$ Gas Sensor", Journal of Optoelectronics and Advanced Material, 13, 1331-1337 (2011).

Shaposnik,D, Pavelko, R, Llobet E, Gispet-Guraid, X., "Hydrogen Sensors on The Basis of $\mathrm{SnO}_{2}-\mathrm{TiO}_{2}$ System", Sensors and Actuator, 194, 527- 534 (2012).

Wang, Z., dan Hu, Y., "Hydrogen Gas Sensors Based on Semikonduktor Oxide Nanostruktur" ,Sensors and Actuator, 174, 527-534 (2012).

Yadav, B.C.,Shukla, T, Sigh, S, "Solid state Titania-Based Gas Sensor For Liquefied Petroleum Gas Detection At Room Temperature", bull material of physics(University of Lucknow, India, 2011), hal 123-126.

Yang, L., Yin, C., Zhang, Z., Zhu, B., AStudy of Hydrogen Sensing Properties and Microstructure for Highly Dispersed $\mathrm{Pd} \mathrm{SnO}_{2}$ Thin Films with High Respon Magnitude", Sensors and Actuator, 34, 74-82 (2014). 